\title{
LA NARRATIVA DE JAVIER MARÍAS EN DIÁLOGO CON EL CINE. CONFLUENCIAS ESTÉTICAS Y HORIZONTES POSIBLES
}

\author{
THE NARRATIVE OF JAVIER MARÍAS IN DIALOGUE WITH \\ CINEMA. AESTHETIC CONFLUENCES AND POSSIBLE \\ HORIZONTS
}

\section{Carmen María LÓPEZ LÓPEZ \\ Universidad Católica de Murcia cmlopez@ucam.edu}

\begin{abstract}
Resumen: El artículo estudia la presencia del cine en distintas novelas de Javier Marías. Esta presencia puede apreciarse no solo en temas y personajes, sino también en referencias explícitas que están involucradas en el centro de la trama. Además de ofrecer un marco teórico acerca de los límites y desafíos de los estudios fílmicos y literarios, el artículo proporciona un análisis los elementos cinematográficos en sus novelas. En síntesis, el estudio pretende llenar un hueco en este enfoque interdisciplinar al que la crítica especializada aún no ha dedicado una reflexión minuciosa.
\end{abstract}

Palabras clave: Javier Marías. Narrativa española contemporánea. Literatura. Cine.

\begin{abstract}
The article studies the presence of cinema in several novels by Javier Marías. This presence is detected not only in topics and characters, but also in explicit references which are central to the plot. As well as providing a theoretical framework about the limits and challenges of filmic and literary studies, the article provides an analysis of the cinematic elements in his novels. In synthesis, the study aims to fill a gap in this interdisciplinary approach to which critics haves not yet paid enough attention.
\end{abstract}

Key Words: Javier Marías. Contemporary Spanish Novel. Literature. 
Cinema.

\section{LA NOVELA EN CONEXIÓN CON EL CINE: INCENTI- VOS Y RAZONES}

Hacia dónde caminan los estudios literarios en el siglo XXI nadie puede decirlo. Complejo sería augurar unas líneas hegemónicas del pensamiento teórico sobre la literatura $\mathrm{y}$, sin embargo, necesario es al menos continuar pensado su intersección con los lenguajes del cine. En esta línea, los enfoques tradicionales en que se ha postulado la superioridad artística o "primado estético" (Sánchez Noriega, 2010: 6) del texto literario como elemento base de un sinfín de transposiciones a la pantalla, conformaron la idea dominante contra la que hubieron de posicionarse las nuevas aproximaciones al fenómeno fílmico, con el fin de reivindicar su autonomía y cualidades intrínsecas. En este sentido, el logocentrismo (prevalencia de la letra escrita sobre otros lenguajes icónicos) como idea imperante en la cultura occidental, situaba en una posición de desprestigio otros enfoques periféricos en los que fuera posible contemplar la validez del Séptimo Arte como verdadero origen y germen de ficciones.

Desde las clásicas monografías (Gimferrer, 1985; Utrera, 1985; Company, 1987; Peña-Ardid, 1992, 2004; Sánchez Noriega, 2000) dedicadas a las relaciones entre literatura y cine, se perpetúa la idea secular de una relación unidireccional (de la literatura al cine) para abordar los lazos fílmico-literarios. Sin embargo, y en contraste con esa visión, la crítica especializada ha dedicado una atención mucho menor al enfoque contrario, es decir, al posicionamiento del foco de estudio en la influencia del cine como origen de ficciones narrativas. Es posible constatar esta idea cuando en nuestras pesquisas bibliográficas prevalece la ausencia de estudios que ahonden en las transposiciones del cine a la literatura, exceptuando los procedimientos cinematográficos que el Séptimo Arte legó a la novela. Hecha la salvedad de la influencia del cine en algunos novelistas desde principios del siglo XX (Peña-Ardid, 1991: 169-191; Sánchez Noriega, 2010: 5-23), la Teoría y la Crítica Literarias carecen aún de enfoques en los que el cine se sitúe como verdadero motor artístico, palanca impulsora de ficciones.

Esta insuficiencia de los modelos teóricos auspiciados en las 
citadas monografías clásicas sobre literatura y cine ha motivado repensar el estatuto de lo cinematográfico en la narrativa española contemporánea, centrado en esta ocasión en el diálogo que la escritura de Javier Marías establece con los lenguajes del cine. Partiendo de un enfoque invertido, el cine se instaura como sustrato fílmico en su obra. De hecho, si atendemos a criterios estrictamente cronológicos, las películas objeto de análisis se insertan en un arco temporal concreto (1940-1965): Recuerdo de una noche (Mitchell Leisen, 1940), El fantasma y la señora Muir (Joseph L. Mankiewicz, 1947), El río (Jean Renoir, 1951), La ventana indiscreta (Alfred Hitchcock, 1954), Vértigo (De entre los muertos) (Alfred Hitchcock, 1958) y Campanadas a medianoche (Orson Welles, 1965). De esta manera, la impronta que el cine ha impreso en la narrativa de Marías permite establecer relaciones sentidas no de modo unidireccional (de la literatura al cine), sino aproximándonos al enfoque inverso, por el que el cine (atendiendo al a cronología y a los testimonios del autor) nutre el marco de referencias de buena parte de sus novelas.

Esta nueva orientación, según atestiguó Pérez Bowie, presenta una infinita riqueza artística y amplía el paradigma de influencias y relaciones entre distintos sistemas artísticos, lo que permite abarcar "por una parte, las influencias de la literatura sobre el cine, la del cine sobre la literatura y la existencia de los numerosos fenómenos de intertextualidad entre ambos" (2004: 276). Tal forma de comparatismo instaura nuevas vías de análisis "entre obras en principio ajenas entre sí pero que, gracias a la mirada ofrecida por la poética de los mundos ficcionales, ofrecen llamativas simetrías en su diseño" (Piñera Tarque, 2009: 240)

A su vez, la línea hermenéutica aquí adoptada es seguida en los distintos estudios aglutinados bajo el marbete "De la literatura al cine: reescrituras fílmicas no convencionales" (Pérez Bowie, 2010), donde se reflexiona acerca de los enfoques inéditos o poco comunes, como por ejemplo las estrategias del cine para transcribir los discursos literarios que expresan el mundo interior de los personajes, lo que implica un mayor grado de sofisticación a la luz de la dificultad que esta práctica lleva aparejada. En la citada relación dinámica entre discursos, el proceso de transformación al que se somete el texto literario respecto de la fuente cinematográfica base implica, más que una simple transcodificación semiótica, una red de vínculos sociales, contextuales y culturales en virtud de una "mutua iluminación semántica" (Doležel, 1999: 291) 
Roto el purismo disciplinar de los estudios literarios, quebrada su especificidad lingüística, derruidas las viejas creencias acerca de la hegemonía del texto verbal en detrimento de otros lenguajes o códigos semióticos, la narrativa de Javier Marías es interpretable a la luz de su intersección con otras artes como el cine. Lejos quedan así los alegatos en favor de la especificidad del estatuto literario, de su imposible impregnación con otros lenguajes artísticos, tal como quedan registrados en Laocoonte de Lessing (1776), quien clama aquí por una purificación de la pintura, liberada así de todo lastre de la palabra:

La pintura y la poesía deberían ser igual que dos vecinos que se llevan muy bien, ninguno de los cuales puede parecer tomarse libertades en el campo del otro, sino que ejercitan un respeto mutuo de sus fronteras y llegan a un acuerdo pacífico respecto a todos esos pequeños asaltos que las circunstancias pueden forzar a cualquiera de los dos a ejercer sobre los derechos del otro (Lessing, 1985: 110).

Así, mermada la soberanía de la palabra, las zonas de contacto e interferencias de la novela con otros medios como el cine legitiman una aproximación a la narrativa desde lugares no avalados previamente por la tradición teórica citada. El teórico o el crítico se ha encontrado ante la necesidad imperiosa de repensar no solo el objeto de estudio, sino también los métodos e instrumentos de análisis. En el deslizamiento epistemológico del qué al cómo, deviene necesario abordar las conexiones entre lenguajes artísticos: literatura y cine.

El cine, arte joven por excelencia, fue uno de aquellos frutos tardíos que se insertaron hace apenas un siglo en el panorama de la moderna teoría literaria. No obstante, nació al amparo de una nutrida tradición teórica, una estirpe de autores y escuelas críticas capaz de sustentar su epistemología desde los ángulos más diversos. Los formalistas rusos, la narratología fílmica, la Semiótica Comparada o los estudios visuales catapultaron un modo de repensar el estatuto de lo literario a la luz de la intersección de los lenguajes del cine en las primeras décadas del siglo XX.

Crítica y crisis, ya lo anunció Roland Barthes, se hermanan en virtud de una misma raíz etimológica. Y en efecto, a menudo los estudios literarios logran renovar sus postulados metodológicos a raíz de profundas crisis internas. Por ello en sus reflexiones en torno al fenómeno fílmico, Peña-Ardid (1992: 13) lamentaba la "orfandad metodológica y 
disciplinaria" ante la que se encuentra el estudioso de las relaciones entre literatura y cine, interrogándose acerca de a quién compete el análisis de estos vínculos: ¿A la Estética, la Semiología, la Teoría de la Comunicación, la Literatura Comparada? Ante esta encrucijada de caminos, apuntaba Genette desde una posición conciliadora: "Si se aman de verdad los textos, se debe desear, de cuando en cuando, amar (al menos) dos a la vez" (Genette, 1989: 42). ¿Cómo amar la unión entre literatura y cine? O más bien, ¿desde qué metodología crítica amar dos artes emparentadas en virtud de la narratividad, del discurso?

Vivimos una situación académica en que las disciplinas y ámbitos de estudio se definen, como bien atestigua Mieke Bal (2004: 12), a partir de "los dominios de sus objetos de estudio": la historia del arte estudió tradicionalmente los objetos artísticos; los estudios literarios, la obra literaria; y el cine, las películas, las distintas cinematográficas y estilos. Cuando los objetos - en este caso la literatura y el cine- se cruzan e hibridan en el marco de los estudios literarios, se requiere un horizonte presidido por la interdisciplinariedad, como reclamaba en los años setenta Roland Barthes (1994: 71), siempre atento a los cambios emergentes en el pensamiento teórico que suelen llevar consigo una modificación en los dominios artístico-literarios. La interdisciplinariedad se proyecta como horizonte metodológico y "sólido valor en la investigación" (Barthes, 1994: 73), en provecho de un lenguaje nuevo, lo que Barthes denomina un "deslizamiento epistemológico" (1994: 74) como huida ante el malestar de la clasificación.

\section{JAVIER MARÍAS Y EL CINE: HORIZONTES POSIBLES}

De acuerdo con este tapiz de ideas, punto de arranque de estas páginas, la articulación de un pensamiento acerca de la narrativa de Javier Marías suscita líneas de intersección con los lenguajes del cine. Sustentamos aquí que el imaginario fílmico se instaura como clave sustancial en una poética de la escritura de Javier Marías (López López, 2019). Como expresó el novelista en el compendio de artículos que versan sobre cine (Donde todo ha sucedido. Al salir del cine, 2005), "también es raro que no haya en ellas [mis novelas] alguna escena o pasaje que, calladamente, no sea deudor de algo contemplado en la oscuridad de una sala y retenido en la memoria para siempre jamás" (Marías, 2005: 30). El Séptimo Arte se ha 
revelado como educador visual de la sensibilidad del novelista:

\begin{abstract}
Marias ha reconocido la influencia que los medios audiovisuales, especialmente el cine, han tenido en su formación literaria y cultural, asi como en la de los escritores de su generación. No es de extrañar entonces que la mirada sea un importante principio ordenador en su narrativa. Los protagonistas unas veces son flâneurs, otras son espectadores de películas, otras veces espían y siempre son observadores muy atentos de lo que les rodea (Cuñado, 2004: 84).
\end{abstract}

Previamente, ya en el célebre artículo "Cabezas llenas" recogido en Literatura y fantasma, Marías (1993: 427) dio cuenta de la importancia de integrar distintos lenguajes o códigos, al hilo de una reflexión sobre la singularidad de los artistas según los instrumentos y cauces expresivos de su creación. Mientras que los pintores tienen la cabeza llena de "imágenes, volúmenes y colores", la cabeza de los músicos está adornada de "notas" y "melodías", así como la de los escritores atesora "principalmente palabras". Esta manera de deslindar y trazar unas fronteras nítidas entre distintas artes supone el punto de inicio de nuevas formas de hibridación según distintos códigos semióticos (verbales, visuales y auditivos), pues como sostiene Marías, aunque la cabeza de los escritores alberga las palabras también está llena "de imágenes, de historias, de argumentos, de personajes, de diálogos, de escenarios, de rimas" (Marías, 1993: 427). Como se deduce de las ideas expuestas, el escritor otorga importancia no solo a las palabras - cauce verbal — sino a las imágenes como impulso visual de su escritura.

Otra idea vinculada a la influencia del cine en su obra es que ser espectador constituye la clave de todo ejercicio intelectual: mirar largamente las cosas para, a fortiori, pensar sobre ellas. En este sentido, la cabeza del escritor otorga un lugar privilegiado a las estrategias visuales, fundamentalmente de índole cinematográfica, aunque también con otras artes como la fotografía (Pittarello, 2017: 353), hecho que conecta las novelas de Marías con imágenes artísticas provenientes del cine, la literatura o la música (Scharm, 2013: 100).

La elección del plural horizontes no es baladí en el presente artículo. Son muchas las líneas que el cine traza en el pensamiento literario de Javier Marías. Una línea posible se alberga en el ya citado libro que compendia artículos periodísticos y ensayos sobre cine: Donde todo ha sucedido. Al salir del cine (2005). Esta línea, en la que no me detendré, aunque en estas 
páginas se haga alusión a ella, constituye un eje de reflexión acerca de la influencia del cine como materia temática, según estudió Steenmeijer (2005: 256) acerca de la faceta de Javier Marías como columnista en prensa (Núñez Díaz, 2011a, 2011b).

Elegiré, en cambio, de los muchos horizontes del discurso fílmico en su obra, el influjo del Séptimo Arte en sus novelas, bifurcado en tres ejes que estimo centrales: el primero, el llamado eje espectatorial (mirar al cine) se detiene en la condición de espectadores o lectoespectadores de sus personajes de ficción; el segundo, eje referencial (contar el cine), profundiza en el modo en que la materia fílmica se inserta a través de la palabra, mediante una verbalización del cine que oscila desde los comentarios explícitos hasta las huellas veladas; el tercero y último, eje imitativo (vivir el cine) explora los mecanismos de autoconsciencia de los personajes de estar imitando — mimetizando- a criaturas de Hitchcock.

\subsection{Eje espectatorial: mirar el cine}

En tanto que ver es pensar con los ojos, ser espectador constituye la actitud primera de toda tentativa intelectual (Martín-Estudillo, 2009: 115). La mirada del personaje-espectador es primordial en un acercamiento a las huellas fílmicas en Mañana en la batalla piensa en mí (1994) ${ }^{1}$. A excepción de algunos estudios (Gelida, 2001; Scarlett, 2004; Grohmann, 2002; Candeloro, 2016; Pérez-Carbonell, 2016a; López López, 2018), esta novela todavía no ha gozado de una aproximación crítica que revele y desvele las claves cinematográficas insertas en la misma. Sin embargo, las películas Recuerdo de una noche (Mitchell Leisen, 1940) y Campanadas a medianoche (Orson Welles, 1965), bien mencionadas por el narrador, bien evocadas de forma no explícita o velada, conforman la materia ficticia de la obra la noche en que Víctor Francés visita a Marta Téllez en Conde de la Cimera, la misma noche en que de manera precipitada y sin causa aparente, muere la mujer.

Uno de los núcleos fílmicos de la novela gravita en torno a la película Recuerdo de una noche (1940) de Mitchell Leisen, cuyo título

${ }^{1}$ Pérez-Carbonell (2016a: 36) ha establecido diversas analogías cinematográficas en Mañana en la batalla piensa en mí: la postura del Deán similar a un actor, la posición de Victoria esperando en la calle propia de una escena fílmica o el insomnio del Solitario en conexión con el motivo del insomnio que padece el Rey en Campanadas a medianoche (1965) de Orson Welles. 
no se cita de manera directa, aunque resulta identificable a partir de las repetidas menciones a sus dos actores principales: Fred MacMurray y Barbara Stanwyck. Esta película se introduce en el relato literario cuando el narrador enciende la televisión del dormitorio de Marta la noche aciaga en que muere. El rostro de los actores es una de las imágenes que Marta Téllez contempla en los minutos finales de su existencia.

El narrador nada dice hasta ahora sobre la película que está viendo en televisión, simplemente anuncia que dejó la televisión sin sonido: "Bajé el sonido de la televisión con el mando antes de ponerla en funcionamiento, y, como yo quería, apareció la imagen sin voz" (Marías, 1994: 15). El carácter de la citada película de Leisen proyectada en televisión dista mucho de ser accesorio. Es mucho más que una referencia fílmica o un modo de ensalzar la cultura cinematográfica de Marías. La televisión encendida sin sonido sugiere en la memoria de los narradores-espectadores un espacio "unificado por imágenes visuales" (Gelida, 2001: 477). De hecho, la lengua española acoge la expresión 'matar el tiempo' asociada al acto de ver la televisión, si bien es el tiempo el que mata a los seres humanos (Scarlett, 2004: 406). Esta idea adquiere relieve la noche en que Marta muere y, de manera irónica, Víctor enciende la televisión para hacer más soportable la espera agónica ante la enfermedad repentina de Marta.

La influencia de la ficción cinematográfica en el modo de concebir los relatos se deja sentir en el imaginario de la novela, en la que se proyecta un salto fundamental en la cultura con la invención y el hallazgo del cinematógrafo:

En los primeros años de nuestro siglo [siglo XX] toma proporciones extraordinarias ese nuevo fenómeno que es el cine. En poco tiempo, el cine logra desarrollar la sensibilidad receptiva del público, de tal modo que éste incorpora a las dos fuentes de evocación visual que tenía - experiencia real y teatro - una nueva dimensión de su capacidad receptora de imágenes narrativas: la de la imagen vista. Hasta entonces, la sensibilidad colectiva estaba habituada a oír narrar, pero con la aparición del cine se habitúa y familiariza fácilmente a ver narrar (Castellet, 2001: 33).

De acuerdo con estas ideas, con el desarrollo del cine como nueva fuente de "evocación visual" (Castellet, 2001: 33) en Mañana en la batalla piensa en mí los personajes ven una película sin voz, pues no interesa tanto lo que se está relatando en términos narrativos (oír narrar) cuanto lo que 
es visualizado en la pantalla (ver narrar). Este hecho supone un cambio sustancial en la recepción de la cultura literaria, de estirpe esencialmente cinematográfica. En otras palabras, da cuenta de la transición de la palabra a la imagen, de modo que el acto de contar ha sido desplazado por el de ver narrar. Este interesante giro en la recepción de las historias con la influencia del referente cinematográfico es comentado por Marías en sus ensayos sobre cine. En la entrada del 30 de diciembre del "Diario de Zürich”, Marías se refiere a este fenómeno de las películas sin voz:

[...] la televisión estaba encendida sin sonido, y durante un rato, distraidamente y mientras hacía otras cosas, fui echándole vistazos. Hago esto a menudo, y es una prueba fatídica para cualquiera: sin voz ni “discurso”, uno ve en seguida qué político está mintiendo, qué escritor no se cree sus propias palabras, quién baila mal o bien, qué actores o actrices son verosímiles o irrepresentables (Marías, 2001: 23).

Del mismo modo, en el artículo "De no haber nacido", publicado en El Semanal (08/02/1998) y recogido en Seré amado cuando falte (1999; 2005: 70-72), Marías rememora el visionado sin voz del clásico de Frank Capra ;Qué bello es vivir! que emitían en televisión como es costumbre durante la Navidad, apelando a esas películas sin voz evocadas en Mañana en la batalla piensa en mí. Si bien el novelista no tenía intención de ver de nuevo esa película, no pudo distanciarse del encanto del rostro de los actores proyectado sobre la pantalla: "sus actores sin voz ni diálogo James Stewart, Lionel Barrymore, Donna Red, Gloria Grahame, Thomas Mitchell, el ángel Henry Travers - captaron mi atención de inmediato y me enganché irremediablemente" (Marías, 2005: 71).

Aunque no se pierde la entidad del relato, la pura visualidad de las imágenes invita al predominio del oír ver sobre el oír narrar, de modo que el arte de contar esas películas siempre es subsiguiente del visionado de las imágenes fílmicas. El comentario deviene fundamental en un estadio posterior, como forma de ordenación mental de una estructura narrativa visualizada en la pantalla.

La ficción fílmica se integra en el relato de Víctor Francés hasta formar un núcleo indisociable, en tanto que su pensamiento reflexivo viene pautado por las distintas menciones a la película de Leisen. Aunque el primero en contemplar el rostro sin voz de Fred MacMurray en la pantalla fue Víctor Francés, al que siguió el rostro de Marta Téllez, en los instantes 
previos a su muerte, también el niño, apoyado en el quicio de la puerta del dormitorio de su madre, contemplará el rostro del actor:

miró hacia la televisión encendida y vio a MacMurray, a quien en esta escena, como en otras desde hacía un rato, acompañaba ahora a Barbara Stanwyck, una mujer de cara aviesa y poco agradable. Debió decepcionarlo el blanco y negro o la ausencia de voces, o que se tratara de MacMurray y Stanwyck en vez de Tintín y Haddock u otras eminencias del dibujo animado (Marías, 1997: 27).

La reflexión sobre la película se integra en el discurso del narrador, en una contigüidad entre la realidad fenomenológica externa y su conciencia. Aun cuando Víctor Francés se dispone a librarse de la existencia de Marta, su discurso mental se desencadena en movimiento, es decir, in itinere (López López, 2017a: 566) mientras camina por la casa de Marta, hasta que abandona Conde de la Cimera. La película de Leisen continúa evocada mentalmente, como si los actores Fred MacMurray y Barbara Stanwyck fueran testigos mudos de lo acontecido esa noche, rostros impertérritos que siguen existiendo en la pantalla aun cuando la vida de Marta expiró el último aliento:

Sali de la alcoba sin apagar la televisión, dejando a MacMurray y a Stanwyck todavia un rato — hasta que durasen - como momentáneos testigos únicos, mudos pero rotulados, de los dos estados de Marta Téllez, su vida y su muerte, y de la mudanza (Marías, 1997: 59).

Si la repetición otorga continuidad a través de los efectos y sensaciones de realidad concedidos a los hechos, en ese afán rememorativo de la noche funesta el narrador evocará el monólogo de Marta previo a su muerte, figurándose los pensamientos póstumos de la difunta sobre Recuerdo de una noche: "Y la televisión emitiendo mientras yo me moría, una película antigua de Fred MacMurray" (Marías, 1997: 35).

La película que, a grandes rasgos, completa el entramado cinematográfico de la novela es Campanadas a medianoche de Orson Welles, película que el narrador ve en la pantalla del salón antes de abandonar Conde de la Cimera. Campanadas a medianoche (Falstaff Chimes at Midnight, 1965) de Orson Welles es una co-producción hispanosuiza a partir de distintas obras de Shakespeare: Ricardo II, las dos partes 
de Enrique IV, Enrique V y Las alegres comadres de Windsor (Scarlett, 2004: 398). Mientras que el filme de Leisen, no citado de manera explícita, entrañaba una notable dificultad interpretativa, la película de Welles es mencionada en el argumento de la novela.

Que Orson Welles es uno de los directores de cine dilectos de Marías se demuestra cuando en la sección "Dos maestros y dos parientes" (Marías, 2005: 85-104) de sus ensayos sobre cine dedicados a homenajear a directores se encuentra, entre otros grandes maestros del Séptimo Arte como J. L. Mankiewicz, A. Hitchcock o J. Ford, la siempre memorable figura del polifacético director estadounidense. Asimismo, en "Campanadas y viento y fantasmas y muertos" (Marías, 2005: 62-64), al incidir en aquellas películas cuya huella es indeleble, menciona dos de las obras maestras de Orson Welles: Campanadas a medianoche y El tercer hombre. En este caso la impronta del cine de Welles sobre la narrativa de Marías resulta más que evidente, a la luz de las innumerables alusiones a sus películas.

Al igual que sucede con la película de Leisen, la obra de Welles se proyecta en la televisión cuando el narrador decide abandonar la casa de Marta en Conde de la Cimera. Antes de marcharse, Víctor ve en televisión un fragmento de esta película y decide dejar la televisión encendida para que cuando se despierte el niño Eugenio, la vida siga sucediendo con total normalidad. "El mundo entero en blanco y negro de madrugada" se convierte como leitmotiv fílmico de Mañana en la batalla piensa en mí.

Más adelante, el Solitario - un personaje que se identifica con la figura del rey - contará que vio incompleta la película de Welles durante una noche de insomnio: "La película trataba de reyes, Enrique IV y Enrique V, el segundo cuando todavía era Príncipe de Gales, Príncipe Hal lo llamaban a veces [...]" (Marías, 1997: 147).

En este punto se rescata la relación entre Falstaff y el Príncipe Hal inherente al drama shakespereano. Como ha expresado Marías (2005: 33), esta escena plasma el momento más desolador de la historia del cine: cuando el Príncipe Hal, que frecuentaba burdeles y se movía en ambientes de dudosa reputación, se convierte en Enrique V y niega a Falstaff como amigo y compañero de vida. 


\subsection{Eje referencial: contar el cine}

La condición inherente de lo cinematográfico en la narrativa de Marías se revela cuando la materia fílmica se instaura como una operación referencial, es decir, mediante la verbalización de imágenes, pasajes o ambientes cinematográficos. Sus novelas, en este sentido, pueden considerarse en cierto modo películas contadas (Marías, 2005: 19), como si el relato del primigenio cine narrativo se trasvasara a su mundo novelístico para forjar un diálogo fruto del contacto entre dos artes.

A diferencia de otros documentos textuales (fotografías, mapas y otras imágenes del arte) con que Marías acompaña sus novelas, el cine se inscribe en una dimensión verbal, al tamiz de la palabra, en un decir sobre las imágenes. En suma, el caudal incesante de interpretaciones, avivado en el caso del cine no por la doble codificación verbal e icónica sino por la imbricación de ambos elementos en las páginas de la novela, ha ofrecido un sugestivo diálogo interartístico, una poderosa polifonía semiótica.

El llamado ciclo de Oxford, tríptico discursivo compuesto por Todas las almas, Negra espalda del tiempo y Tu rostro mañana, integra un haz de motivos fílmicos (Herzberger, 2011). En cuanto a la primera de ellas, Todas las almas, buena parte del material literario con que Javier Marías configuró el personaje de Clare Bayes y su infancia en la India, en una región bañada por las aguas del río Yamuna o Yumna, tiene unos orígenes confesamente cinematográficos que remiten a El río (Le Fleuve, 1951) del cineasta francés Jean Renoir. En el artículo "Si no han visto el río" (Marías, 2005: 37-39), el escritor hace patente la impronta que la película de Renoir dejó en Todas las almas:

Yo sé bien, por ejemplo, que un importante episodio de mi novela Todas las almas, una escena en un puente ferroviario sobre el río Yamuna o Jumna que atraviesa la ciudad de Delhi en la India, no habría existido si en mi cabeza no estuviera siempre presente la atmósfera de una de mis películas predilectas, El río de Jean Renoir. Y esa misma escena, en la que dos personas debieron saltar desde el puente al agua y sólo una de ellas lo hizo, también está relacionada con Vértigo de Hitchcock, como no es difícil de suponer (Marías, 2005: 30).

Si bien la película de Renoir y la novela de Marías carecen de un vínculo de fidelidad o similitud presentativa, existen ciertas asociaciones 
en los modos de concebir mundos ficticios, en una tensión entre los mundos complementarios y los mundos polémicos (Doležel, 1999: 288). En efecto, la reescritura del episodio de ambientación renoiriana se acerca a la idea de un mundo complementario tal como lo entiende Doležel, por cuanto se añaden núcleos argumentales, se modifica la historia germinal y se agregan niveles diegéticos. Así pues, la historia de Clare Bayes y del narrador de Todas las almas cristaliza como un romance temporal, un adulterio anodino sin mayor trascendencia cuando el narrador abandone la ciudad de Oxford. A diferencia de esta construcción diegética, la película de Renoir se centra en la historia de la desilusión tras el primer amor, en una exploración en el significado místico y religioso en el que se asienta la confrontación entre Oriente y Occidente (Bazin, 1974: 113).

Este enfoque se distancia del concepto de fidelidad de la nueva obra respecto de la obra base. La proto-obra (la película de Renoir) y la reescritura (Todas las almas) se perfilan como mundos polémicos en la medida en que el protomundo ha rediseñado su estructura y reinventado la historia (Doležel, 1999: 288). Se aprecian así ciertos elementos de transgresión que apuntan a una rivalidad entre el nuevo mundo de ficción y el protomundo canónico.

En Negra espalda del tiempo pueden apreciarse algunos temas y motivos (el fantasma o el hilo de continuidad entre lo vivos y los muertos) sobre los que el novelista ha reflexionado a propósito de algunas películas de Hitchcock (en concreto, Rebeca, 1940) y, de manera más evidente, El fantasma y la señora Muir (1947) de Joseph L. Mankiewicz. El tema de los vivos y los muertos, en relación con la figura del fantasma aflora en el artículo "El fantasma y la señora Muir" (Marías, 2005: 49-61), sin olvidar la referencia en "Música en la retina"" (Marías, 2005: 76-78) donde evoca la película de Mankiewicz — junto a otras de Hitchcock - para resaltar la figura de Bernard Herrmann, el compositor wagneriano que impregna tanto de "escalofríos" como de "lirismo" las obras (Marías, 2005: 77). El filme de Mankiewicz es nuevamente evocado en el artículo "Campanadas y viento y fantasmas y muertos" (Marías, 2005: 62-64), al que se refiere como la película "más desoladora y a la vez más feliz de la historia del cine" (Marías, 2005: 62).

2 Publicado en El Semanal (05/05/1996) y recogido en Mano de sombra (1997). 
De todo ellos "El fantasma y la señora Muir"3 (2005: 49-61) es, sin ambages, uno de los artículos nucleares sobre temática cinematográfica albergados en este libro, así como uno de los textos de mayor proyección en sus novelas a partir de los vasos comunicantes entre vivos y muertos. $\mathrm{Su}$ importancia no radica únicamente en el comentario denso y extenso de una película que versa sobre una historia de amor entre una mujer y un fantasma, a la manera de la ghost story anglosajona como género dilecto en la Inglaterra victoriana (Binh, 1994: 174). Por encima de este hecho interesa resaltar la proyección que la figura del fantasma - no solo como tema sino también como instancia comunicativa entre vivos y muertosrevela por su potencialidad en el quicio comparativo entre el discurso literario y el discurso fílmico.

Como ha estudiado Pérez-Carbonell (2016b), las novelas de Marías rescatan personajes de condición fantasmal: vivos sometidos a un proceso de encantamiento como Víctor Francés en Mañana en la batalla piensa en mí o Jaime Deza en Todas las almas y Tu rostro mañana, fantasma a causa del alejamiento físico (de Madrid) y emocional (de Luisa). Otras veces estos personajes ya no pertenecen al mundo de los vivos $\mathrm{y}$, sin embargo, permanece un indeleble hilo de continuidad que conecta ambos planos ontológicos. El discurso de los narradores de Marías, fundamental en el ciclo de Oxford, se erige como hilo discursivo en cuya voz reposan vivos y muertos, un hontanar de historias sobre la pérdida irremisible y la esperanza incierta. El narrador del ciclo hilvana en su voz los ecos fantasmales de los muertos: Cromer-Blake y Toby Rylands en Todas las almas, la hija de Juan Benet o al pequeño Julianín (a los que sobreviven los objetos) en Negra espalda del tiempo, y Peter Wheeler y Juan Deza (su padre) en Tu rostro mañana. Este motivo que rescatan los narradores de Marías procede, en buena medida, del legado cinematográfico de dos películas principalmente, las que según el novelista mejor han explorado el tema de la relación o comunicación entre vivos y muertos: El fantasma y la señora Muir de Joseph L. Mankiewicz (2005: 50) y Dublineses de J. Huston (2005: 62).

De las películas citadas esta comunicación entre vivos y muertos se plasma con gran vigor en la obra de Mankiewicz, donde la relación entre una mujer y un fantasma al suspenderse la credulidad en virtud del

${ }^{3}$ Publicado primero en Écrire le cinéma (1995) y seguidamente en Vida del fantasma (2001). 
carácter fantasioso de la ghost story, ofrece cierto halo de esperanza: la señora Muir y el fantasma del capitán pueden dialogar, aunque su tiempo juntos sea breve. Sin embargo, el halo de esperanza pronto se quiebra con el advenimiento de la despedida irrevocable entre dos seres que pertenecen a esferas ontológicamente opuestas.

Los resortes cinematográficos en la obra de Marías se dejan sentir en Berta Isla (2017), la última novela publicada hasta ahora. Perpetuando la estela de otros personajes atraídos por el cine (pensemos en Víctor Francés en Mañana en la batalla piensa en mí, Jaime Deza en Tu rostro mañana o Eduardo Muriel en Así empieza lo malo), Berta es aficionada al cine $\mathrm{y}$, de manera muy lúcida, compara el temperamento irascible y violento de Tom - tras hablar de la escena del Enrique $V$ de Shakespeare- con un actor de wéstern como Walter Brennan. El recuerdo del rostro de este actor en distintas películas que vio en la Filmoteca, clásicos como Pasión de los fuertes, Río Rojo y Río Bravo (2017: 284), conecta en su memoria estableciendo una psicoanalogía (Cohn, 1978) entre ambos personajes. Es frecuente, asimismo, la caracterización física de personaje a partir de la evocación de actores de cine: el pelo de Tomás Nevinson — según expresa el narrador - "recordaba al del actor secundario Dan Duryea y se acercaba al del actor principal Gérard Philipe" (Marías, 2017: 18).

Las diversas menciones a actores de cine continúan durante el primer encuentro entre Tomás y Tupra, cuando el agente del servicio secreto británico le enseña distintas fotos de posibles sospechosos, por si Tomás puede identificarlos: el mentón de uno de ellos le hace evocar a Christopher Lee cuando interpretaba a Holmes y a Drácula (Marías, 2017: 117). En otro episodio, tras la visita de Vera Rowlands, el narrador reflexiona sobre cómo Nevinson, inquieto y suspicaz, esperaba la llegada de alguien que desvelara su engaño, su falsa identidad. Menciona en este punto a Lee Marvin y Clu Gulager en la película The Killers de Don Siegel, por la situación similar con los dos sicarios.

Si bien estas menciones se albergan en la novela sin integrarse plenamente en la trama, mayor conexión con el cine se ofrece a partir de la historia de Martin Guerre y la inclusión de la película francesa $E l$ regreso de Martin Guerre (Le retour de Martin Guerre, Daniel Vigne, 1982), núcleo significativo introducido por Berta en la parte central de la novela. Las referencias literarias y fílmicas a la historia de Martin Guerre recuperan el motivo de la comunicación entre los vivos y los muertos, a 
partir de las recreaciones artísticas citadas por Berta: la película El regreso de Martin Guerre basada en una historia real del siglo XVI y, desde el ángulo literario, la novela La mujer de Martin Guerre (1941) de Janet Lewis:

[...] una película francesa que vi poco después y que gozó de popularidad, El regreso de Martin Guerre. Era de 1981 o 1982 pero debi de verla en 1984, cuando venci mis resistencias y finalmente me atrevi: varias personas me habian hablado de ella y su tema me causaba temor. Estaba basada en una historia real, acontecida en el sur de Francia, muy cerca de España, en el siglo XVI, y también — supe luego - en una excelente novelización de 1941, La mujer de Martin Guerre, escrita por una autora americana para mi desconocida hasta entonces (pese a mis clases y a mi especialidad), Janet Lewis (Marías, 2017: 374-375).

El regreso de Martin Guerre (Daniel Vigne, 1982) aborda el tema de los visos de suplantación que puede tener un regreso, sobre cómo al cabo de muchos años el hombre que regresa se asemeja mucho al que se marchó y al mismo tiempo lo distancia de él un abismo, con la suspicacia de una posible suplantación. El punto que conecta la nouvelle de Lewis y la película francesa de Daniel Vigne (1982) radica en que a Berta le hablan y aconsejan primero la película sobre Martin Guerre y solo después descubre que está basada en la novelita de Janet Lewis. Lejos de resultar resolutiva, Berta deja en la hipótesis si el relato de Martin Guerre sobre el que ella reflexiona procede de la película, de la novela o de un libro de una profesora innominada. Sin embargo, tampoco importa explorar la fuente directa de la que se nutre el discurso de Berta, sino más bien constatar que ambas recreaciones artísticas (la de Janet Lewis y la de Daniel Vigne), orientan sus ideas y estilemas en la misma dirección:

Ya no sé si todo esto lo relataba la película, la novela de cuarenta años antes o un libro de 'microhistoria' posterior, de una profesora de Princenton, que asimismo me molesté en leer una vez atravesado el umbral del miedo y despertada mi curiosidad. Probablemente lo relataban los tres, ninguno se apartaba en lo fundamental del resto, ninguno faltaba a la verdad (Marías, 2017: 375).

Berta Isla sitúa en pie de igualdad las ficciones literaria y fílmica, pues ambas recrean una historia concomitante a su propia existencia, 
colmando de significación el discurso tejido por la espera, aún en la incertidumbre de un posible regreso. En síntesis, el relieve que la materia fílmica adquiere en la narrativa de Javier Marías permite tender puentes entre discurso literario y discurso fílmico.

\subsection{Eje imitativo: vivir el cine}

Imitar es una de las pulsiones ancestrales del ser humano. Aristóteles situó la mimesis en el centro de su Poética para significar así el predominio de esta condición en detrimento de la poiesis, la creación o el genio. Llevado este concepto al pensamiento literario de Marías, en el ensayo titulado "Autobiografía y ficción" (1993: 70-78) recogido en Literatura y fantasma, el novelista hace extensible la idea a las ficciones vistas en el cine. En esta línea, en Así empieza lo malo Juan de Vere es un personaje autoconsciente de estar imitando (mimetizando comportamientos, gestos, actitudes o estilos de vivir y actuar) de personajes de Hitchcock: "Tal vez yo imitaba ahora a criaturas de Hitchcock” (Marías, 2014: 191).

Las ficciones de Hitchcock y Marías participan de la significación del ojo (Bataille, 1994: 54) como un elemento esencial en su construcción simbólica e imaginaria (Sanabria, 2011). Una ventana, el quicio de una puerta o el umbral que separa dos espacios constituyen el incentivo suficiente para que, en los personajes mirones, espías, detectives, todo ellos seres con una curiosidad exacerbada, aflore la pulsión escópica (Lakhdari y Enache, 2014) de su mente asociativa y enfermiza. A este respecto, Rodríguez Fisher (2004: 75) ha dedicado una reflexión exhaustiva a la condición de narrador-espía de Jaime Deza, personaje que "mira para ver y contar: un traductor de vidas o anticipador de historias".

Los procesos semióticos que conectan cine y literatura implican como punto de partida la existencia de un "protomundo canónico" (Doležel, 1999: 312), a partir del cual se modela un nuevo mundo de ficción. Si como sostiene Doležel (1999: 282), en la naturaleza semiótica de los mundos ficcionales se ofrece una cadena de sucesión, "complementándose, reforzándose, o compitiendo y minándose unos a otros", películas de Hitchcock como La ventana indiscreta (1954) y Vértigo (1958) se instauran como proto-obras a partir de las que es posible establecer un vínculo con pasajes literarios de Todas las almas y Tu rostro mañana.

En concreto, la estética de la contemplación en el ciclo de Oxford de 
Javier Marías ofrece dos momentos culminantes vinculados por un espacio común: el museo Ashmolean de Oxford en Todas las almas y el Museo del Prado que visita Deza en Tu rostro mañana para espiar a Custardoy y donde contempla el cuadro Las edades y la muerte de Hans Baldung Grien (Poncelet, 2010; Pérez Carbonell, 2016a). Estos pasajes a su vez ofrecen concomitancias con el mundo ficcional representado por Hitchcock en Vértigo (de entre los muertos), cuando Scottie espía a Madeleine y ese ser fantasmagórico visita un museo para contemplar el retrato de su bisabuela difunta Carlota Valdés.

De un modo muy notable Así empieza lo malo se asemeja a la estructura ficcional y al modelo de mundo planteado por Hitchcock en Vértigo, como fue puesto de relieve en el estudio "Reescribir el Vértigo (de entre los vivos): la impronta cinematográfica de Hitchcock en Asi empieza lo malo, de Javier Marías" (López López, 2017b: 269-290): hay el triángulo de personajes (Juan de Vere, Beatriz Noguera y Susana) similar al que forman Scottie, Judy y Madeleine; hay dos detectives, dos mujeres de las cuales una es la simulación o repetición de la otra por su parecido físico y finalmente mueren (2017b: 273).

La novela, a su vez, ofrece capítulos de acción desbordante marcados por la persecución, hecho que la interconecta con obras de la filmografía de Hitchcock como Vértigo (De entre los muertos) o Con la muerte en los talones. Los detectives, quienes en un principio salvan la vida a las mujeres, acaban teniendo una relación carnal con los personajes femeninos a los que habían estado espiando. En los episodios de espionaje del joven de Vere tras los pasos de Beatriz en el santuario de Nuestra Señora de Darmstadt, prevalece toda una dinámica visual, un escenario de ventanas indiscretas, una plasticidad en la construcción del discurso que recuerda de manera incesante los ángulos visuales de las películas del genio del suspense.

El cine como vivencia se filtra en el enhebrado de la trama a modo de imitación de distintos escenarios provenientes del cine de Hitchcock. Esta evocación de lugares y espacios cinematográficos alcanza un relieve indiscutible cuando Juan de Vere, por encargo de Muriel, inicia el espionaje de Beatriz Noguera y llega hasta el Santuario de Nuestra Señora de Darmstadt, recuperando memorables escenarios hitchcockianos:

No sé muy bien por qué [...] el ambiente del lugar me recordó vagamente 
al de la casa en la que estuvo y no estuvo Cary Grant secuestrado una tarde en Con la muerte en los talones, y a la vez, con ser muy diferentes $y$ de países distintos - pero los autores con estilo dejan en todo su huella y unifican lo divergente-, al de la zona por la que se aventuraba James Stewart en Londres buscando a un tal Ambrose Chappell en El hombre que sabía demasiado, acababa de verlas en un ciclo Hitchcock de la Filmoteca al que Muriel me había arrastrado sin esfuerzo, decía que había que frecuentar sin cesar sus películas porque a cada visión se descubría y aprendía algo nuevo, inadvertido en las anteriores (Marías, 2014: 166).

Si bien las coordenadas históricas y espaciales han cambiado, la recuperación de los escenarios del cine de Hitchcock - explicitados en Con la muerte en los talones y El hombre que sabía demasiado, pero extensibles como veremos a Vértigo (de entre los muertos)—, se asocian al santuario de Nuestra Señora de Darmstadt en el que Juan de Vere espía por primera vez a Beatriz Noguera. Al hilo de esta idea Jordi Gracia (2009: 277) apuntó que la "espléndida morosidad meditativa" del relato se funde en las novelas de Marías con una creciente "tensión narrativa", sostenida a lo largo de muchas páginas. Estos elementos antitéticos en apariencia (la reflexión meditativa que se expande y la tensión intensiva que sostiene la acción en la intriga y el suspense) logran que sus novelas no puedan interpretarse únicamente como un thriller de intriga de naturaleza policíaca, ni se reduzcan tampoco a novelas-ensayo de tempo lento.

En este sentido, el espionaje como patrón narrativo de las películas de Hitchchcock es motivo que vincula el modo de actuar de Juan de Vere al de los memorables actores hitchcockianos: Cary Grant en Con la muerte en los talones y James Stewart en El hombre que sabía demasiado. Los espías cerebrales de Hitchcock cuya visión atenta sobre la realidad es también un pensamiento acerca de la misma, se asimilan al comportamiento de Juan de Vere en la novela de Marías, espía curioso que camina por las calles de Madrid tras los pasos de Beatriz Noguera.

\section{HACIA UNAS CONCLUSIONES}

Pensar el cine desde las coordenadas de una poética que exceda los rígidos preceptos de la adaptación literaria ha sido el propósito inicial de esta línea de estudios. Distanciándose del paradigma tradicional de 
las adaptaciones cinematográficas de obras literarias ${ }^{4}$, en la escritura de Javier Marías el cine se sitúa como origen de ficciones. Es el cine el que alumbra la literatura, dotándola de una significación renovada, obligando a mirar el texto literario con ojos nuevos, bajo una luz distinta. Al contacto y desde el conocimiento de diversas claves fílmicas, el crítico puede perfilar un singular bosquejo de su literatura, que no es documento muerto sino testimonio vivo de voces que dialogan con los lenguajes del cine, a través de la libre recreación de motivos fílmicos.

A lo largo de estas líneas he tratado de demostrar el modo en que en las novelas de Marías se deja sentir la huella de distintas películas, a veces mencionadas de modo específico y otras como apropiación de una escena memorable, a menudo de difícil identificación pese a que sus perfiles remiten a un mundo contemplado en la pantalla. Alfred Hitchcock, Orson Welles, J. L. Mankiewicz o Jean Renoir constituyen algunos de sus referentes acorde con el gusto estético del autor.

En este sentido, a la renovación discursiva de la novela - en su lenguaje, composición, formas y estilos-, contribuye la educación visual de narradores como Marías, novelista influenciado por el cine como elemento integrante de su marco de referencias culturales. Lotman decía en Cultura y explosión que los textos innovadores están escritos en una lengua cuyo código aún no se ha creado. Lengua sin código que revela un modo de hacer explosionar los pliegues del lenguaje. Al interconectarse con los códigos del cine, la escritura de Javier Marías invita a redefinir los volubles perfiles del arte. El cine, como expresó muy bellamente Lotman, nos habla, nos habla con muchas voces que forman contrapuntos muy complejos. Nos habla y quiere que lo escuchemos. También los

\footnotetext{
${ }^{4}$ Cabe mencionar la adaptación de Todas las almas (1989), que fue llevada al cine bajo el título El último viaje de Robert Rylands (1996) por Gracia Querejeta. Como atestigua Kercher (1997: 102), Marías mostró un enorme descontento con el resultado, y así lo manifiesta en dos artículos publicados en noviembre de 1996 en El País: "El novelista va al cine" (Marías, 2005: 216-219) y "El novelista sale del cine" (Marías, 2005: 220-222), recogidos posteriormente en Donde todo ha sucedido. Al salir del cine (2005). Su descontento viene motivado porque la adaptación cinematográfica no respeta la esencia del libro. De hecho, la película introduce elementos inexistentes en el libro, como la relación homosexual explícita entre Cromer Blake y Toby Rylands. Aunque por sus labores como traductor Javier Marías es consciente de la dificultad para trasladar un texto a otra lengua, el novelista se plantea, según explica Miguel Marías, "si hay necesidad de que exista también como película lo que ya es satisfactorio y suficiente en forma de libro" (Marías, 2005: 19). Otra adaptación más reciente es la del cuento Mientras ellas duermen (1990), llevada al cine por Wayne Wang: Mientras ellas duermen (2016) (Gaviña, 2012).
} 
personajes de Marías, cinéfilos y contempladores atentos de todo cuanto sucede, dialogan con el cine. Es el caso de Jaime Deza, el narrador del ciclo de Oxford ${ }^{5}$, quien en Tu rostro mañana atribuye a su discurso la condición de un legado cinematográfico, como si hubiera escuchado todas sus palabras en el cine, conformando así un nudo indisociable entre la vida y la experiencia cinematográfica: "Todas estas frases que hemos visto pronunciar en el cine las he dicho yo o se las he oído a otros a lo largo de mi existencia, esto es, en la vida, que guarda mucha más relación con las películas y la literatura de lo que se reconoce normalmente y se cree" (Marías, 2013c, 29-30).

\section{REFERENCIAS BIBLIOGRÁFICAS}

ARISTÓTELES (2010). Poética. Nueva reimpresión, traducción, introducción y notas de Alicia Villar Lecumberri. Madrid: Alianza.

BAL, M. (2004). "El esencialismo visual y el objeto de los estudios visuales". Estudios visuales 2, 11-50.

BARTHES, R. (1994). El susurro del lenguaje. Más allá de la palabra y de la escritura. Barcelona: Paidós.

BATAILLE, G. (1994). Historia del ojo. México: Ediciones Coyoacán.

BAZIN, A. (2006). ¿Qué es el cine? Madrid: Rialp.

(1974). Jean Renoir. W. H. Allen: Virgin Books.

$\overline{\mathrm{BINH}}, \mathrm{N}$. T. (1994). Joseph L. Mankiewicz. Madrid: Cátedra.

BLANCA, I. (2013). "Prólogo". En Las huellas dispersas, Javier Marías, 11-15. Barcelona: De Bolsillo.

CANDELORO, A. (2012). Como la nieve resbaladiza. Javier Marías narratore del tempo. Roma: Aracne.

\footnotetext{
${ }^{5}$ El marbete ciclo de Oxford es el rótulo que engloba Todas las almas (1989), Negra espalda del tiempo (1998) y Tu rostro mañana (2002-2007), esta última compuesta a su vez de sucesivas entregas -Tu rostro mañana 1. Fiebre y lanza (2002), Tu rostro mañana 2. Baile y sueño (2005) y Tu rostro mañana 3. Veneno y sombra y adiós (2007), denominación surgida antes con una voluntad editorial que, con un propósito inherente a lo literario, en la edición de 2013 en De Bolsillo. No obstante, en Figuraciones del yo en la narrativa. Javier Marías y Enrique Vila-Matas (2010), Pozuelo Yvancos se anticipó al referirse a él como "ciclo Deza" (Blanca, 2013: 11), si bien ha sido ciclo de Oxford el marbete que ha cuajado al permitir la inclusión de Negra espalda del tiempo pese a que Deza no aparezca en ella ni como narrador ni como personaje. En la actualidad la crítica (Scharm 2013, Pozuelo Yvancos, 2017) suele referirse a estas novelas con la condición de ciclo.
} 
(2016). Javier Marías y el enigma del tiempo. Murcia: Universidad de Murcia.

CASTELlET, J. M. a (2001). La hora del lector. Barcelona: Península.

COHN, D. (1978). Transparent Minds: Narrative Modes for Presenting Consciousness in Fiction. Princeton: Princeton University Press.

COMPANY, J. M. (1987). El trazo de la letra en la imagen. Texto literario y texto filmico. Madrid: Cátedra.

CUÑADO, I. (2004). El espectro de la herencia. La narrativa de Javier Marías. Amsterdam / New York: Rodopi.

DOLEZEL, L. (1999). Heterocósmica. Ficción y mundos posibles. Madrid: Arco / Libros.

GAVIÑA, S. (2012). "Wayne Wang llevará al cine Mientras ellas duermen, de Javier Marías". ABC, 10 de octubre. Disponible en línea: http:// www.abc.es/20121010/cultura-libros/abci-wayne-wangllevaracine-201210091743.html [13/11/2016].

GELIDA, R. (2001). "Literatura de indagación: Cultura visual, televisión y el sujeto en Mañana en la batalla piensa en mí, de Javier Marías". Revista Hispánica Moderna 54.2, 474-491.

GENETTE, G. (1989). Figuras III. Barcelona: Lumen.

GIMFERRER, P. (1985). Cine y literatura. Barcelona: Planeta.

GRACIA, J. (2009). "Pensar por novelas. Tu rostro mañana de Javier Marías". En Allí donde uno diría que ya no puede haber nada. Tu rostro mañana de Javier Marías, A. Grohmann y M. Steenmeijer (eds.), 61-65. Amsterdam / NewYork: Rodopi.

GROHMANN, A. (2002). Comings into One's Own. The Novelistic Development of Javier Marias. Amsterdam / New York: Rodopi.

GROHMANN, A. y STEENMEIJER, M. (eds.) (2009). Alli donde uno diría que ya no puede haber nada. Tu rostro mañana de Javier Marías. Amsterdam / New York: Rodopi.

HERZBERGER, D. K. (2011). A companion to Javier Marías. Woodbridge: Tamesis.

KERCHER, D. (1997). "Children of the European Union, Crossing Gendered Channels: Javier Marías's novel, Todas las almas, and Gracia Querejeta's El último viaje de Robert Rylands". Cine-Lit 3, 100-112.

LAKHDARI, S. y ENACHE, I. (2014). Voir, se voir, être vu. La pulsion scopique dans la litterature hispanique contemporaine. París: 
Indigo.

LESSING, G. E. (1985) [1776]. Laocoonte o sobre los límites en la pintura y la poesía. Traducción, prólogo y notas de Enrique Palau. Barcelona: Orbis.

LÓPEZ LÓPEZ, C. M. (2015). "El cine como clave cultural y hermenéutica en la narrativa de Javier Marías: una lectura de Así empieza lo malo". En La diversidad en la literatura, el cine y la prensa española contemporánea, F. López Criado (ed.), 287-294. Santiago de Compostela: Andavira.

(2017a). "Caminar al ritmo del pensamiento: el monólogo in itinere en Tu rostro mañana de Javier Marías". En Topografía literarias. El espacio en la literatura hispánica de la Edad Media al siglo XXI, A. Agraz Ortiz y S. Sánchez-Hernández (eds.), 565-574. Madrid: Biblioteca Nueva.

(2017b). "Reescribir el Vértigo (De entre los vivos): la impronta cinematográfica de Hitchcock en Así empieza lo malo, de Javier Marías". Signa. Revista de la Asociación Española de Semiótica 26, 269-290. Disponible en línea: http://revistas.uned.es/index. php/signa/article/view/19956 [10/02/2020].

(2018). "Películas sin voz y otros insomnios: Claves fílmicas en Mañana en la batalla piensa en mí, de Javier Marías". En El texto de las mil caras: hibridismo y nuevas tendencias en la literatura española e hispanoamericana, D. García Ponce y L. Pache Carballo (eds.), 283-297. Sevilla: Renacimiento.

(2019). El cine en el pensamiento y la creación de Javier Marías. Vigo: Editorial Academia del Hispanismo.

LOTMAN, I. (1999). Cultura y explosión. Barcelona: Gedisa.

MARÍAS, J. (1990). Mientras ellas duermen. Madrid: Alfaguara.

(1993). Literatura y fantasma. Madrid: Siruela.

(1997). Mañana en la batalla piensa en mí. Madrid: Alfaguara. (2001) "Diario de Zürich". En El pensamiento literario de Javier Marías, M. Steenmeijer (ed.), 11-28. Amsterdam / New York: Rodopi.

(2005). Donde todo ha sucedido. Al salir del cine. Barcelona: Galaxia Gutenberg. (2013a). Negra espalda del tiempo. Barcelona: De Bolsillo. (2013b). Todas las almas. Barcelona: De Bolsillo. 
(2013c). Tu rostro mañana. Barcelona: De Bolsillo. (2014). Así empieza lo malo. Barcelona: Alfaguara. (2017). Berta Isla. Barcelona: Alfaguara.

MARTÍN-ESTUDILLO, L. (2009). "Del pensamiento visual al pensamiento literario". En Allí donde uno diría que ya no puede haber nada. Tu rostro mañana de Javier Marías, A. Grohmann y M. Steenmeijer (eds.), 115-132. Amsterdam / NewYork: Rodopi.

NÚÑEZ DÍAZ, P. (2011a). Las colaboraciones de Javier Marías en la prensa. Opinión y creación. Madrid: UNED.

(2011b). "Acerca del propio oficio: Una mirada a la obra periodística de Javier Marías". Signa. Revista de la Asociación Española de Semiótica 20, 497-515. Disponible en línea: http://revistas.uned. es/index.php/signa/article/view/6276 [10/02/2020].

PEÑA ARDID, C. (1991). "La influencia del cine en la novela española del medio siglo: una revisión crítica". Cuadernos de Investigación Filológica 17, 169-191.

(1992). Literatura y cine. Una aproximación comparativa. Madrid: Cátedra.

(2004). "Los estudios de literatura y cine en España (1995-2003).

Ensayo de bibliografía". Signa. Revista de la Asociación Española de Semiótica 13, 237-275. Disponible en línea: http://revistas.uned. es/index.php/signa/article/view/6096/5831 [10/02/2020].

PÉREZ BOWIE, J. A. (2010). "Sobre reescritura y nociones conexas. Un estado de la cuestión". En Reescrituras filmicas: nuevos territorios de la adaptación, J. A. Pérez Bowie (ed.), 2143. Salamanca: Ediciones Universidad de Salamanca.

PÉREZ-CARBONELL, M. (2016a). The Fictional World of Javier Marías. Language and Uncertainty. Leiden / Boston: Brill / Rodopi.

(2016b). "Ghosts as Storytellers: Absences and the Phantasmagorical Nature of Javier Marías's Narrators". Bulletin of Hispanic Studies 93.5, 495-509.

PIÑERA TARQUE, I. (2009). Mundos narrativos. Relato literario y relato filmico. Kassel: Reichenberger.

PITTARELLO, E. (2009). "Sobre las fotos". En Alli donde uno diría que ya no puede haber nada. Tu rostro mañana de Javier Marías, A. Grohmann y M. Steenmeijer (eds.), 95-113. Amsterdam-New York: Rodopi. 
(2017). "Retratos de familia en Negra espalda del tiempo de Javier Marías". En L'écrivain à l'œuvre dans le récit de fiction espagnol contemporain, N. Noyaret y A. Paoli (eds.), 353-366. Binge (France): Éditions Orbis Tertius.

PONCELET, N. (2010). El tema de la mirada en Todas las almas de Javier Marias. Nordersted: Grin Verlag.

POZUELO YVANCOS, J. M. (2010). Figuraciones del yo en la narrativa: Javier Marías y E. Vila-Matas. Valladolid: Cátedra Miguel Delibes. (2017). Novela española del siglo XXI. Madrid: Cátedra.

SANABRIA, C. (2011). Contemplación de lo intimo: lo audiovisual en la cultura contemporánea. Madrid: Biblioteca Nueva.

SÁNCHEZ NORIEGA, J. L. (2000). De la literatura al cine. Teoría y análisis de la adaptación. Barcelona: Paidós.

(2010). "De los literatos descontentos a los escritores-cineastas y los relatos fílmico-literarios". Arbor. Ciencia, Pensamiento y Cultura 186.741, 5-23. Disponible en línea: http://arbor.revistas.csic.es/ index.php/arbor/article/view/749 [10/02/2020].

SCARLETT, E. (2004). "Victors, Villains and Ghosts: Filmic Intertextuality in Javier Marías's Mañana en la batalla piensa en mi". Revista Canadiense de Estudios Hispánicos 28.2, 391-410.

SCHARM, H. (2013). El tiempo y el ser en Javier Marías: el Ciclo de Oxford a la luz de Bergson y Heidegger. Amsterdam / New York: Rodopi.

STEENMEIJER, M. (2005). "Javier Marías, columnista: el otro, el mismo”. En Javier Marías, I. Andrés y A. Casas (eds.), 255-273. Universidad de Neuchâtel: Arco Libros.

UTRERA, R. (1985). Escritores y cinema en España: un acercamiento histórico. Madrid: Ediciones JC.

\section{FILMOGRAFÍA}

HITCHCOCK, A. (1954). La ventana indiscreta (Rear Window). Estados Unidos: Paramount Pictures.

(1956). El hombre que sabia demasiado (The Man Who Knew Too Much). Estados Unidos: Paramount Pictures.

(1958). Vértigo (De entre los muertos). Estados Unidos: Paramount Pictures. 
(1959). Con la muerte en los talones (North by Northwest). Estados Unidos: Metro-Goldwyn-Mayer.

LEISEN, M. (1940). Recuerdo de una noche (Remember the Night). Estados Unidos: Paramount Pictures.

MANKIEWICZ, J. L. (1947). El fantasma y la señora Muir (The Ghost and Mrs. Muir). Estados Unidos: 20th Century Fox.

OLIVIER, L. (1955). Ricardo III (Richard III). Reino Unido: London Films.

QUEREJETA, G. (1996). El último viaje de Robert Rylands. España: Alta Films / Elías Querejeta P.C.

RENOIR, J. (1951). El río (Le fleuve). Francia: Coproducción India-USAFrancia: Theter Guild / Oriental International Film.

VIGNE, D. (1982). El regreso de Martin Guerre (Le retour de Martin Guerre. Francia: Production Marcel Dassault / France 3 / S.F.P.C.

WANG, W. (2016). Mientras ellas duermen (While the Women Are Sleeping). Japón: Toei.

WELLES, O. (1965). Campanadas a medianoche (Falstaff - Chimes at Midnight). España: España-Suiza-Francia; Alpine Films / Internacional Films.

Recibido el 15 de enero de 2020.

Aceptado el 13 de abril de 2020. 